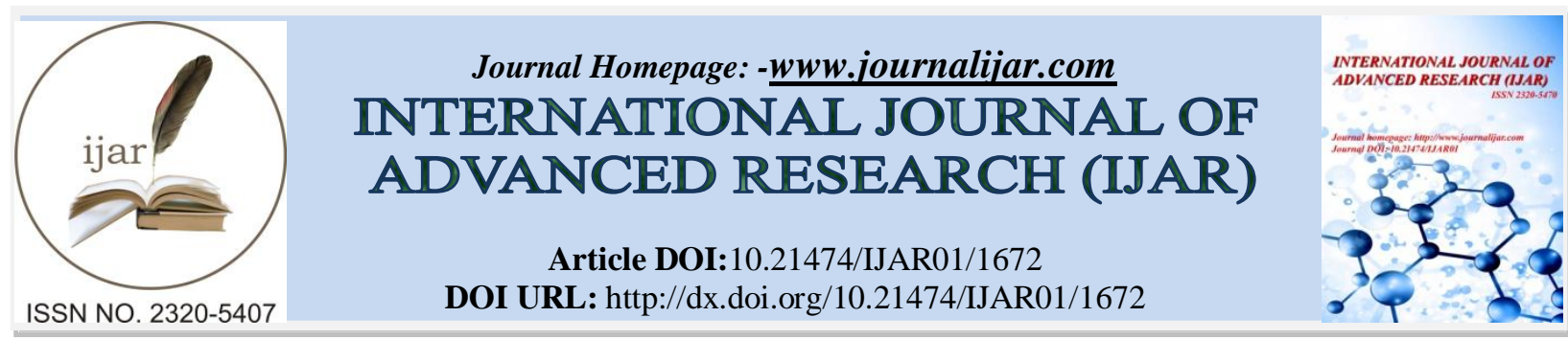

RESEARCH ARTICLE

\title{
FOLLICULAR FLUID HOMOCYSTEINE WITH ACETYL CYSTEINE SUPPLEMENTED OVARIAN STIMULATION: CORRELATION WITH OOCYTE YIELD AND ICSI CYCLE OUTCOME.
}

\author{
S. A. Hebishaand H.M. Mahmoud.
}

Lecturer of Gynecology, Alexandria university Faculty of Medicine, Alexandria, Egypt.

\section{Manuscript Info}

Manuscript History

Received: 15 July 2016

Final Accepted: 26 August 2016

Published: September 2016

Key words:-

N-Acetyl cysteine, homocysteine, follicular fluid, ICSI, Clinical pregnancy rates.

\section{Abstract}

Objective:- to evaluate the impact of N-Acetyl cysteine supplementation during controlled ovarian hyperstimulation on follicular fluid homocysteine and to correlate the results with ICSI cycle parameters particularly oocyte yield and cycle outcome in terms of clinical pregnancy rates.

Subjects and Methods:- 90 women prepared for ICSI using long agonist protocol randomized to receive $\mathrm{N}$-Acetyl cysteine or placebo during stimulation.

Results:-Mean follicular fluid homocysteine level was $4.4 \mathrm{mg} / \mathrm{L}$ in supplemented group versus $6.6 \mathrm{mg} / \mathrm{L}$ in non-supplemented group and this was statistically significant. $(p<0.0001)$ Number of oocytes retrieved and clinical pregnancy rates were also significantly higher in supplemented group. (19 versus 12 and $73 \%$ versus $49 \%)(\mathrm{p}<0.001$, and $<0.03$ respectively)

Conclusion:-Supplementing long agonist controlled ovarian hyperstimulation with $600 \mathrm{mg}$ of oral NAC improved oocyte yield and increased clinical pregnancy rates in ICSI cycles. This favorable impact is correlated, and probably partially explained by reducing follicular fluid homocysteine.

Copy Right, IJAR, 2016,. All rights reserved.

\section{Introduction:-}

Several studies reported positive impact of N-Acetyl cysteine (NAC) used as an adjuvant to clomiphene citrate ovulation induction in cases of polycystic ovary syndrome (PCOS). (Salehpour et al., 2012) These encouraging results, stimulated further research in which NAC was tried as an adjuvant to gonadotropins during controlled ovarian hyperstimulation $(\mathrm{COH})$.(Cheraghi et al.,2014) The main draw-backs of these studies, were the lack of specific outcome measure, the simultaneous administration of other medications and being largely limited to PCOS patients. Recently NAC was tried in non-PCOS ICSI patients. (Elgindy et al.,2010) Although clinical pregnancy rates did not significantly improve, early and late granulosa cell apoptosis, recognized as important prognosticator of oocyte quality, were marginally reduced with NAC. None of these studies has proposed a clear coherent hypothesis explaining this positive impact of NAC, although explanations related to its anti-oxidant properties, have been suggested. Another putative role of NAC might be the reduction in the concentration of the harmful homocysteine in follicular fluid similar to its impact on plasma Hcy. Intravenous infusion of NAC has been reported to cause dramatic decline in plasma Hcy coupled with 10 fold increase in its urinary excretion. (Ventura et al., 1999) Oral administration was found to be equally effective. (Ventura et al.,2003) Homocysteine (Hcy) is a non-proteinforming, sulfur-containing amino acid that functions as a key intermediate in the so called, one carbon metabolism, 
which involves also methionine (Met), and cysteine (Cys) and which utilizes folic acid and cobalamin as co-factors. (Natalie et al.,2003) Therefore, Hcy is a central molecule in folate, methionine and glutathione cycles all of which are profoundly involved in reproductive physiology.(Forges et al.,2008, Ebisch et al.,2007) High plasma homocysteine levels have been correlated not only with vascular endothelial injury and atherogenesis but also with various cell line dysfunction, and apoptosis. (Kim et al.,2006) (fig 1)

Fig 1:-Cycle production of homocysteine.

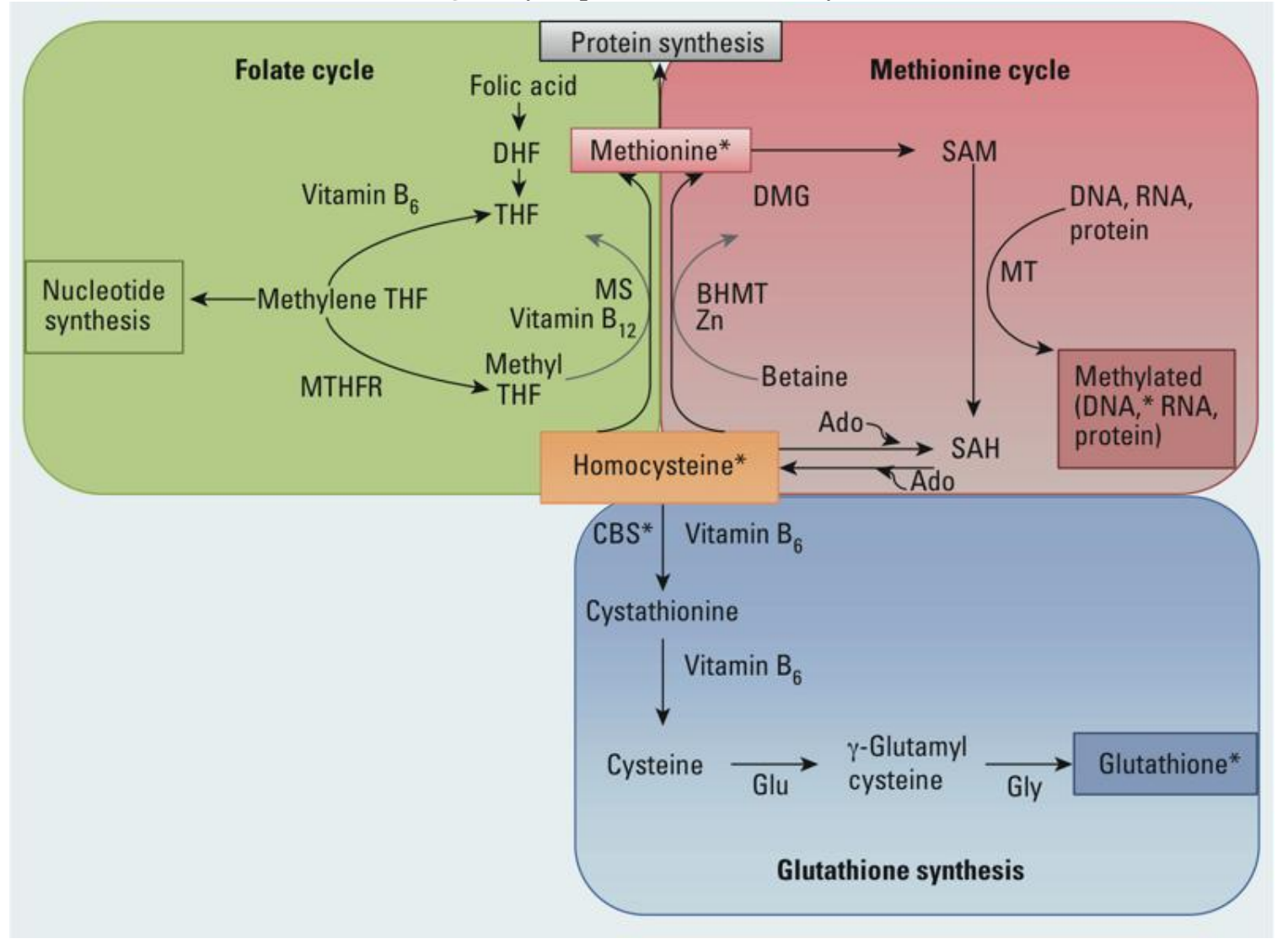

It is similarly plausible to speculate that high local concentrations of homocysteine might be noxious to the viability and function of surrounding cells. The current study was, therefore, conducted to examine the impact of NAC supplementation during $\mathrm{COH}$ on follicular fluid Hcy and correlate the results to ICSI cycle outcome.

\section{Patients and Methods:-}

Design:-Prospective controlled study

Setting:- 90 women were recruited for the study among the patients prepared for ICSI in private center in Alexandria, Egypt between 1/ 2013, and 1/2014.

The study was explained to them and written informed consent for participation was obtained. Inclusion criteria: age between 25 and 35, BMI not more than 35, male factor infertility doing ICSI using fresh semen sample.

Exclusion criteria:- PCOS, endometriosis, and previous ovarian surgery reducing ovarian reserve, and AMH less than $1.5 \mathrm{ng} / \mathrm{ml}$.

After basal sonographic evaluation to rule out the presence of exclusion criteria and to assess the antral follicle count (AFC), all cases were stimulated using the long agonist protocol starting from mid-luteal phase of previous cycle using decapeptyl $0.1 \mathrm{mg}$ subcutaneously. Stimulation was started using 300IU of hMG starting from first day of menses with suppression confirmed by E2 $<50 \mathrm{pg} / \mathrm{ml}$. Participants were randomized to receive N-Acetyl cysteine or 
placebo starting from stimulation day one till the day of hCG. . N-acetyl cysteine was administered in the dose 600 mg effervescent sachets once daily. The study group was designed as group A and the control group as group B. All cases were monitored as usual using sonographic examination and hormonal evaluation including E2 and P4 values. The dose of stimulation was adjusted controlled by response till hCG criteria are achieved. Ovum pick-up was performed 34-36 hours after 10,000 IU hCG. Follicular fluid after oocyte identification and removal was pooled and sent for homocysteine measurement. ICSI procedure was completed as usual and embryo transfer was done on day 3 with cryopreservation of surplus embryos.

Quantitative determination of total homocysteine (HCY) was done using the ADVIA Centaur ${ }^{\circledR}$ System which is a competitive immunoassay using direct chemi-luminescent technology. The different forms of homocysteine in the patient sample are reduced to free HCY by the Reducing Reagent. Free homocysteine is then converted to Sadenosyl homocysteine (SAH) by the Enzyme Reagent. Converted SAH from the patient sample competes with SAH covalently coupled to paramagnetic particles in the Solid Phase for a limited amount of acridinium esterlabeled anti-SAH in the Lite Reagent. Expected Values range from 3.7 to13.9 $\mu \mathrm{mol} / \mathrm{L}$ Statistical analysis was done using SPSS software version 20.

\section{Results:-}

Base line data of the included women were comparable regarding age, BMI, and infertility duration. Ovarian reserve as evaluated using AMH and antral follicle counts were also comparable. (Table 1)

Table 1:-Base line data of the two study groups:

\begin{tabular}{|c|c|c|c|}
\hline Parameter & Group A (n=45) & Group B $(\mathrm{n}=45)$ & p \\
\hline Age (y) & $31.1 \pm 5.5$ & $29.8 \pm 4.8$ & 0.8 \\
\hline BMI & $32.3 \pm 2.5$ & $31.4 \pm 3.8$ & 0.3 \\
\hline Infertility duration (y) & $6.5 \pm 4.0$ & $5.3 \pm 4$ & 0.2 \\
\hline AMH (ng/ml) & $2.3 \pm 1.9$ & $2.6 \pm 2.1$ & 0.2 \\
\hline AFC & $18 \pm 5$ & $16 \pm 7$ & 0.2 \\
\hline
\end{tabular}

Stimulation days, number of ampoules of hMG, serum E2 and P4 on day of hCG were also comparable between the two study groups. (Table 2)

Table 2:-Cycle Data of the study groups.

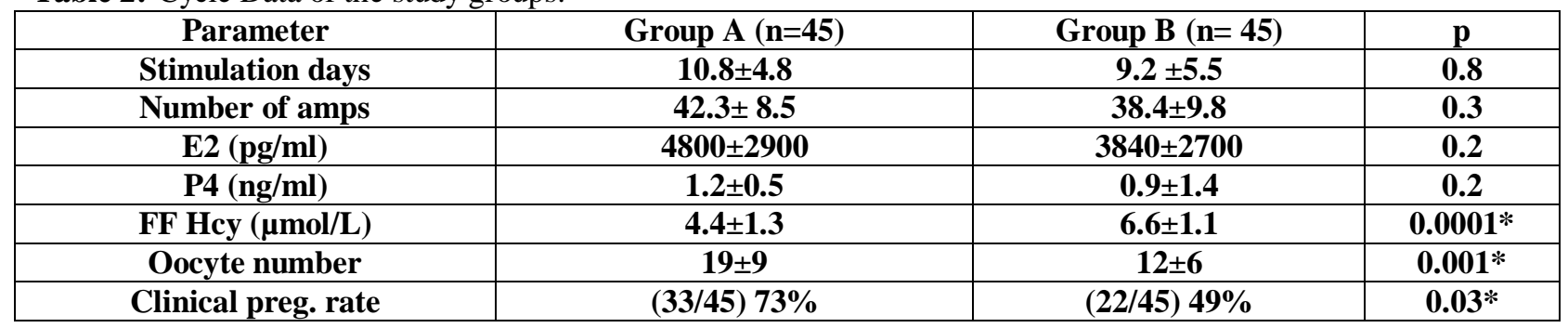

Follicular fluid homocysteine level was significantly lower in the study group (group A) 4.4 versus $6.6 \mu \mathrm{mol} / \mathrm{L}$. (p 0.0001) (Table 2)

The number of oocytes retrieved was significantly higher in the study group (19 versus 12) and ultimately clinical pregnancy rate was significantly higher $73 \%$ versus $49 \%$ ) (p 0.03) (Table2)

\section{Discussion:-}

This is the first report of lower follicular fluid homocysteine concentrations in women who received oral NAC during $\mathrm{COH}$. The study also reports significantly higher oocyte yield and significantly superior ongoing pregnancy rate in the same group.

Ovarian stimulation, per se, has been reported to derange blood and follicular fluid biomarkers of the homocysteine pathway. [14] Several studies reported that high follicular fluid Hcy levels have detrimental effects on follicular development and subsequently on oocyte and embryo quality. (Boxmeer et al.,2008, Berker et al.,2009, Boxmeer et al.,2009) 
The mechanisms of homocysteine induced cell damage are not fully understood but they include; oxidative stress, inducing inflammation through cyclo-oxygenase -2 (COX-2) activation, causing DNA dysfunction through formation of DNA adducts, interfering with protein synthesis, and ultimately causing cell death (apoptosis) through reactive oxygen species (ROS) mediated mitochondrial pathways.(Szymański et al.,(2003) Pushpakumar et al., 2014, Lee et al.,2013)

The threshold value for harmful homocysteine concentration is controversial. Preliminary reports indicate that age and gender differences are significant. (Jakubowski H.,2004, Refsum et al.,2006)

It might also be speculated that tissue susceptibility is variable and that rapidly proliferating cells are more sensitive. This might imply that harmful concentrations are readily reached in follicular fluid during $\mathrm{COH}$ cycle, and that lowering these concentrations via NAC might therefore have positive impact on granulosa cell functions and subsequently on oocyte and embryo quality.

In conclusion; women receiving oral NAC as an adjuvant during $\mathrm{COH}$ in preparation for ICSI have lower follicular fluid homocysteine. This reduction in the concentration of the noxious homocysteine in follicular fluid seems to have positive impact on oocyte yield and quality and subsequently on embryo quality and ultimately on ICSI cycle outcome in terms of ongoing pregnancy rates.

\section{References:-}

1. Berker B, Kaya C, Aytac R, Satiroglu H. (2009) Homocysteine concentrations in follicular fluid are associated with poor oocyte and embryo qualities in polycystic ovary syndrome patients undergoing assisted reproduction. Hum Reprod. 24(9):2293-302.

2. Boxmeer JC, Steegers-Theunissen RP, Lindemans J, Wildhagen MF, Martini E, Steegers EA, Macklon NS.(2008) Homocysteine metabolism in the pre-ovulatory follicle during ovarian stimulation. Hum Reprod. 23(11):2570-6.

3. Boxmeer JC, Macklon NS, Lindemans J, Beckers NG, Eijkemans MJ, Laven JS, Steegers EA, Steegers-Theunissen RP.(2009) IVF outcomes are associated with biomarkers of the homocysteine pathway in monofollicular fluid. Hum Reprod. 24(5):1059-66.

4. Cheraghi E, Mehranjani MS, Shariatzadeh MA, Esfahani MH, Ebrahimi Z.(2014) N-Acetylcysteine improves oocyte and embryo quality in polycystic ovary syndrome patients undergoing intracytoplasmic sperm injection: an alternative to metformin. ReprodFertil Dev. Nov 13.

5. Elgindy EA, El-Huseiny AM, Mostafa MI, Gaballah AM, Ahmed TA.(2010) N-acetyl cysteine: could it be an effective adjuvant therapy in ICSI cycles? A preliminary study. Reprod Biomed Online. 20(6):789-96.

6. Ebisch IM, Thomas CM, Peters WH, Braat DD, Steegers-Theunissen RP. (2007)The importance of folate, zinc and antioxidants in the pathogenesis and prevention of subfertility. Hum Reprod Update. 13(2):163-74.

7. Forges T, Pellanda H, Diligent C, Monnier P, Guéant JL.(2008) Do folates have an impact on fertility? GynecolObstetFertil. 36(9):930-9.

8. Jakubowski H. (2004) Molecular basis of homocysteine toxicity in humans. Cell Mol Life Sci. 2004 Feb; 61(4):470-87.

9. Kim DJ, Koh JM, Lee O, Kim NJ, Lee YS, Kim YS, Park JY, Lee KU, Kim GS.(2006) Homocysteine enhances apoptosis in human bone marrow stromal cells. Bone. 39(3):582-90.

10. Lee YS, Lee SJ, Seo KW, Bae JU, Park SY, Kim CD.(2013) Homocysteine induces COX-2 expression in macrophages through ROS generated by NMDA receptor-calcium signaling pathways. Free Radic Res. 47(5):422-31.

11. Natalie C. Chen,Fan Yang,Louis M. Capecci, ZiyuGu,Andrew I. Schafer, William Durante, Xiao-Feng Yang,and Hong Wang.(2010) Regulation of homocysteine metabolism and methylation in human and mouse tissues. FASEB J. Aug 24(8): 2804-2817.

12. Pushpakumar S, Kundu S, Sen U. (2014) Endothelial dysfunction: the link between homocysteine and hydrogen sulfide. Curr Med Chem. 21(32):3662-72.

13. Refsum H, Nurk E, Smith AD, Ueland PM, Gjesdal CG, Bjelland I, Tverdal A, Tell GS, Nygård O, Vollset SE. (2006) The Hordaland Homocysteine Study: a community-based study of homocysteine, its determinants, and associations with disease. Nutr. 136 (6 Suppl):1731S-1740S.

14. Salehpour S, Sene AA, Saharkhiz N, Sohrabi MR, Moghimian F.(2012) N-Acetylcysteine as an adjuvant to clomiphene citrate for successful induction of ovulation in infertile patients with polycystic ovary syndrome.J ObstetGynaecol Res. 38(9):1182-86

15. Szymański W, Kazdepka-Ziemińska A.(2003) Effect of homocysteine concentration in follicular fluid on a degree of oocyte maturity. Ginekol Pol. 74(10):1392-6.

16. Ventura P, Panini R, Pasini MC, Scarpetta G, Salvioli G.(1999) N -Acetyl-cysteine reduces homocysteine plasma levels after single intravenous administration by increasing thiols urinary excretion. Pharmacol Res. Oct; 40(4):345-50.

17. Ventura P, Panini R, Abbati G, Marchetti G, Salvioli G.(2003) Urinary and plasma homocysteine and cysteine levels during prolonged oral N-acetylcysteine therapy. Pharmacology. 68(2):105-14. 